\title{
Relationship between overweight, obesity and sleep disorders in adolescents from selected cities of Upper Silesia, Poland
}

\author{
Iwona Lizończyk ${ }^{1, A-D \oplus}$, Jadwiga Jośko-Ochojska,A,E-F๑ \\ ${ }^{1}$ Chair and Department of Medicine and Environmental Epidemiology, Medical University of Silesia, Katowice, Poland \\ A - Research concept and design, B - Collection and/or assembly of data, C - Data analysis and interpretation, \\ $D$ - Writing the article, $E$ - Critical revision of the article, $F$ - Final approval of article
}

Lizończyk I, Jośko-Ochojska J. Relationship between overweight, obesity and sleep disorders in adolescents from selected cities of Upper Silesia, Poland. Ann Agric Environ Med. 2021; 28(1): 193-197. doi: 10.26444/aaem/118706

\begin{abstract}
Introduction. Overweight and obesity affect an increasing number of children and adolescents in Poland. This excessive body weight usually coexists with sleep disorders and other afflictions, which is worrisome.

Objective. The aim of the study was to assess the prevalence of overweight, obesity, and sleep disorders among adolescents and demonstrate their relationships.

Materials and method. The study included 1,002 students. Nutritional habits and subjective assessment of sleep were evaluated with the author's survey; daytime sleepiness and sleep quality were assessed with Epworth Sleepiness Scale (ESS) and Sleep Quality Scale (SQS). Statistical calculations were performed with the STATISTICA 12.0 programme.

Results. $24.7 \%$ of adolescents suffered from overweight or obesity, $38 \%$ reported sleep problems in subjective assessment, $10.5 \%$ exhibited excessive daytime sleepiness, determined by ESS, and $14.3 \%$ had impaired quality of sleep as determined by SQS. Gender affected all the discussed problems. Type of school affected all the above, except for daytime sleepiness. In the group with overweight and obesity, $46.6 \%$ of individuals reported sleep problems in subjective assessment. About $59.1 \%$ of adolescents reported chronic fatigue. Reduced concentration and difficulties in learning were reported in $36.3 \%$ of all students, and in $46 \%$ of students with overweight and obesity.

Conclusions. The problem of excess body weight is a very alarming phenomenon since it affects almost $1 / 4$ of the students. Almost half of the students with overweight and obesity reported sleep problems, which is strongly correlated with the type of school. Furthermore, excess body weight influenced the prevalence of reduced concentration and learning difficulties among adolescents.
\end{abstract}

\section{Key words}

obesity, overweight, sleep disorders, adolescents

\section{INTRODUCTION}

The rapidly growing number of overweight and obese persons around the world is one of the most serious hazards for health and is considered to be epidemic by the World Health Organization (WHO) [1]. According to WHO estimates, worldwide obesity has nearly tripled since 1975. In 2016, more than 1.9 billion adults were overweight and over 650 million were obese. Data related to adolescents are particularly alarming since it is estimated that the share of overweight and obese children and adolescents aged 5-19 has risen dramatically from 4\% in 1975 to over $18 \%$ in 2016 [2]. According to the results of a European Health Interview Study (EHIS), 36.6\% of Polish adolescents suffer from overweight and $16.7 \%$ from obesity [3], and the numbers are growing [4].

Adolescents with excess body weight may also suffer from sleep disorders of various types. The qualifying tool designed for clinicians diagnosing sleep disorders is the International Classification of Sleep disorders (ICSD-3), developed by the American Academy of Sleep Medicine. ICSD-3 contains several dozen disease entities grouped into six categories [5].
Many studies show relationship between eating and sleep disorders, although the majority concern adults [6]. However, in the last 10 years, the problem of sleep disorders has increased considerably among young people. Reports show a decline in adolescents' sleep with a rising occurrence of insomnia-related symptoms, excessive tiredness and fatigue $[7,8]$. Lower school performance was associated with these symptoms. It is estimated that in Poland as much as $60 \%$ of people under 25 years of age may be affected [9]. Abnormal sleep is demonstrated as both a consequence and a cause of overweight and obesity among adolescents $[10,11]$.

Since puberty is a period of increased risk in the prevalence of these types of disorders, and due to the increasing obesity epidemics among children and adolescents in Poland, the authors decided to carry out their own study on this topic.

\section{OBJECTIVES}

The aim of the study was to evaluate overweight, obesity and sleep disorder prevalence among adolescents of the Silesian Province, and demonstrate their relationship. 


\section{MATERIALS AND METHOD}

The research included 1002 students - 487 girls (48.6\%) and 515 boys (51.4\%) - during January 2014 - June 2016. Participation in the study was voluntary and anonymous (participants provided verbal informed consent) and involved adolescents between the ages of $16-18$ years (mean $=17.0 \pm 0.8$ years). The studied adolescents attended upper-secondary schools in 3 selected cities of the Upper Silesian Province with more than 100,000 inhabitants: Bytom, Zabrze and Gliwice. Among the types of upper-secondary schools attended there were high schools, technical schools and vocational schools. The study was approved by Bioethical Commission (No. KNW/0022/KB/223/14).

The research included a questionnaire comprised of 3 parts for individual completion. The first part was the author's survey which had been submitted previously for validation. It consisted of data related to the respondent (gender, body weight, height, and age) and 50 questions related to nutritional choices, as well as the occurrence of sleep problems (yes/no type of answers), chronic fatigue, and concentration disorders as part of the subjective assessment.

BMI index was calculated based on body weight (mean= $67.3 \pm 14.1 \mathrm{~kg})$ and height $($ mean $=173.0 \pm 9.6 \mathrm{~cm})$ given in the authors' survey. Since ranges of BMI values were developed for adults, in the case of children and adolescents (up to 18 years old) growth charts including current standards of height, body weight, and BMI index were applied. The study was based on standards developed by the WHO and the CDC (Centers for Disease Control and Prevention) [12]:

BMI $<5$ centiles - underweight;

$\mathrm{BMI} \geq 5$ centile and $<85$ centile - normal body weight;

$\mathrm{BMI} \geq 85$ centile and $<95$ centile - overweight;

BMI $\geq 95$ centile - obesity.

Based on the analysis of growth charts, a group of overweight (BMI $\geq 85$ percentile and $<95$ percentile) and obese (BMI $\geq 95$ centile) persons was identified (study group), and compared to the group of adolescents with normal body weight (BMI $\geq 5$ centile and $<85$ centile) as the control group. Underweight persons (BMI $<5$ centile) were not taken into consideration in the study.

In the research, the sleep disorder occurrence was studied by measuring the tendency to daytime sleepiness using Murray's Epworth Sleepiness Scale (ESS) [13] and the quality of sleep using the SQS questionnaire [14], as consecutively second and third parts of the questionnaire. Moreover, the subjective assessment of sleep was considered as part of the previously described author's survey. The Epworth Sleepiness Scale (ESS) is used to define the level of an individual's sleepiness. It specifies the probability of taking a nap during the day in 8 different, but typical situations - from the most to the least - that contribute to falling asleep. ESS considers values lower or equal to 10 as normal, whereas scores above 10 indicate excessive daytime sleepiness $[15,16]$.

The third part was the Sleep Quality Scale (SQS), which consists of 14 questions evaluating sleep parameters (sleep duration, regularity, number of awakenings). It was developed based on sleep diagnostic criteria according to the Diagnostic and Statistical Manual of Mental Disorders IV (the standard classification of mental disorders by the American Psychiatric Association), and allows for the identification of a group of persons suffering from impaired sleep quality. Using 4 variants of response, it was possible to score 14-56 points.
The minimum value (14 points) indicates the best quality of sleep, whereas the maximum value (56 points) indicates the worst quality of sleep. Values below or equal to 35 points are considered normal [14].

Statistical analysis. The gathered data, after being entered into a database and controlled for correctness, were submitted to statistical analysis with the STATISTICA 12.0 package. Descriptive statistics were preliminarily calculated for the study groups (number of group members, percentage fractions for qualitative variables, the mean value for quantitative variables, standard deviation). The results are presented in the form of Tables or Figures. Comparisons between groups have been made for quantitative variables using the t-test. U-Mann Whitney's test was applied in the case of failure to meet the assumptions. The Chi-squared test with proper modifications dependent on the number of groups was used for qualitative variables. A value of $<0.05$ was considered to be significant for all analyses.

\section{RESULTS}

Overweight and obesity. Overweight and obesity were present in $24.7 \%$ of all the subjects. In this group, as many as $14 \%$ of the individuals suffered from overweight and $10.7 \%$ were obese. This group was compared to the control group of persons with normal body weight (75.3\%). Underweight persons $(2.8 \%)$ were excluded from the study.

It was shown that overweight and obesity are related to gender. Boys had statistically higher BMI than girls $(\mathrm{p}=0.00)$. Overweight and obesity was found in $28.5 \%$ of boys and $20.7 \%$ of girls. Normal body weight was reported in $71.5 \%$ of boys and $79.3 \%$ of girls.

Figure 1 presents the statistically significant $(\mathrm{p}=0.02)$ relationship between BMI class and type of school. Regarding abnormal body weight, the highest number of persons- $27.8 \%$ (of whom $13.9 \%$ persons overweight, 13.9\% with obesity)attended technical schools (TECH), 26.7\% (17.2\% overweight and $9.5 \%$ with obesity) vocational schools (VS), and $19.8 \%$ (11.4\% overweight and $8.4 \%$ with obesity) high schools (HS).

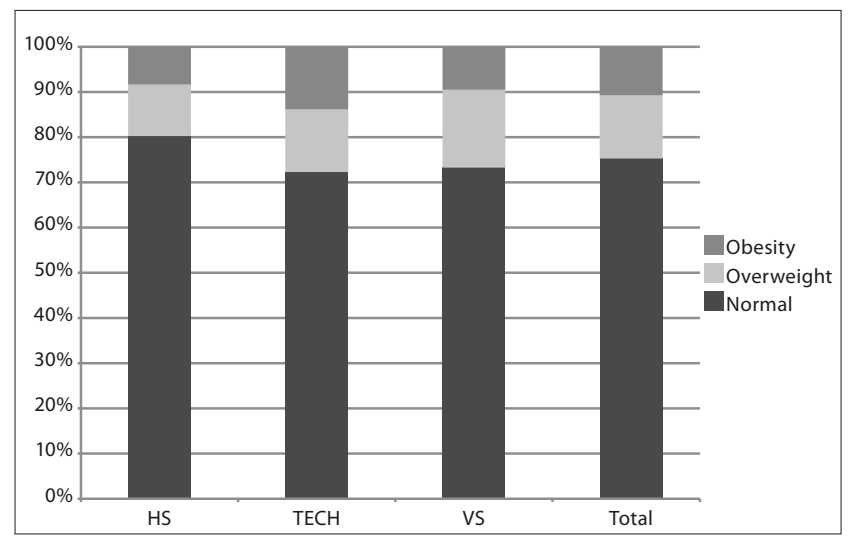

Figure 1. BMI class and type of school

Sleep disorders. In the group of adolescents, 38\% reported sleep problems in the subjective assessment. Mean ESS score was $5.70 \pm 4.00$ points. Excessive daytime sleepiness (ESS score $>10$ points) was exhibited by $10.5 \%$ of persons. Mean sleep quality score determined by SQS was $28.08 \pm 7.38$ points. 
$14.3 \%$ of adolescents were identified with impaired sleep quality (SQS score $>35$ points).

Sleep problems reported in the subjective assessment were not significantly related to gender $(\mathrm{p}=0.4)$, while the relationship was shown between ESS and SQS scores and gender. ESS-assessed daytime sleepiness was significantly higher in girls $(6.30 \pm 3.88$ points) compared to boys $(5.15 \pm 4.03$ points) $(\mathrm{p}=0.00)$. In the group of adolescents, $13.5 \%$ of girls and $7.7 \%$ of boys exhibited excessive daytime sleepiness. Considering the SQS scores, the quality of sleep in girls was shown to be statistically significantly worse $(29.40 \pm 7.15$ points) than in boys ( $26.86 \pm 7.38$ points) $(\mathrm{p}=0.00) .20 \%$ of girls and $8.9 \%$ of boys were identified with impaired sleep quality.

Figure 2 shows that the prevalence of subjectively assessed sleep problems is related to the type of school the adolescents attended. The highest prevalence of sleep disorders was observed among students of technical schools (51.6\%), lower in vocational schools (35.9\%) and the lowest in high schools (23.3\%).

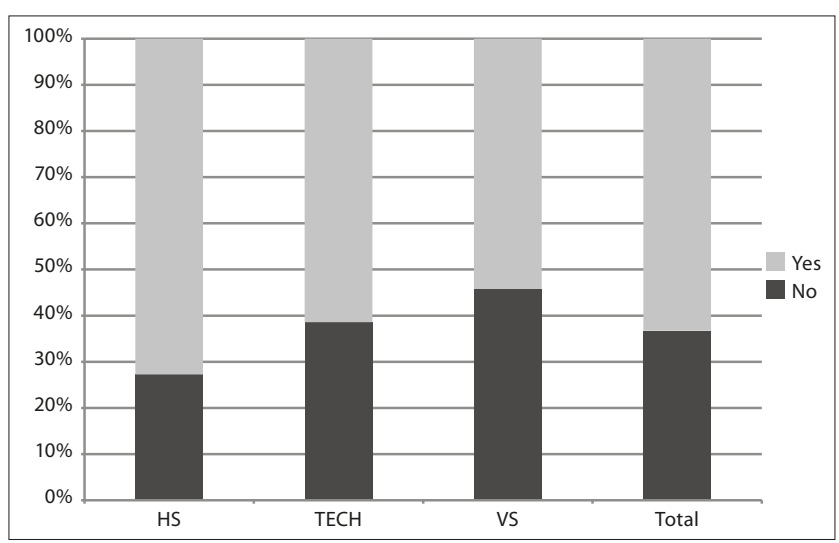

Figure 2. Subjectively assessed sleep problems and type of school

No statistically significant relationship was found between ESS scores and type of school $(\mathrm{p}=0.16)$. However, there was a relationship between the quality of sleep assessed by SQS and the type of school attended by adolescents. In the vocational schools, sleep quality was statistically significantly $(\mathrm{p}=0.02)$ worse $(29.10 \pm 8.37$ points $)$ than in technical schools (27.78 \pm 7.09 points) and high schools ( $27.57 \pm 6.73$ points) (Fig. 3).

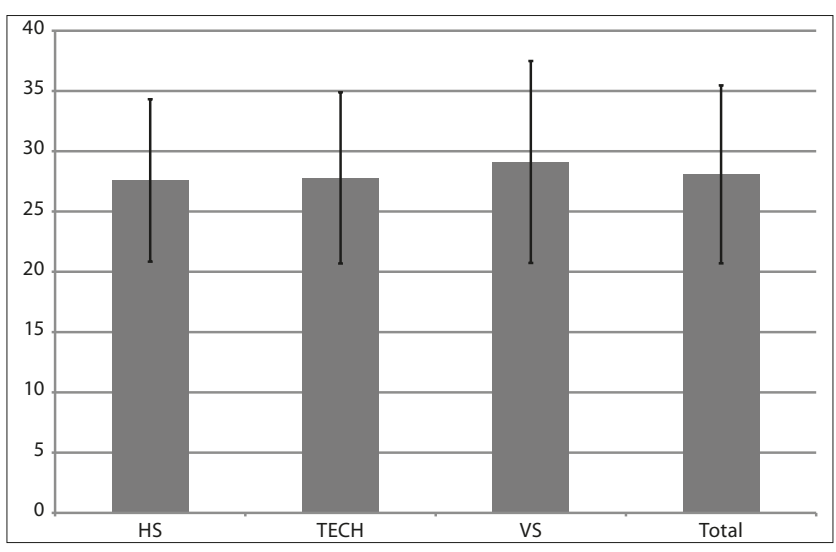

Figure 3. SQS score and type of school

Overweight, obesity and sleep disorders. The study showed a statistically significant $(\mathrm{p}=0.00)$ relationship between excess body weight and the occurrence of subjectively assessed sleep problems. Sleep problems were reported in $46.6 \%$ of persons with overweight and obesity (the study group) and $34.6 \%$ of persons with normal body weight (the control group) (Table 1).

Table 1. Subjectively assessed sleep problems in the study and the control group

\begin{tabular}{lccc}
\hline \multirow{2}{*}{ Group } & \multicolumn{3}{c}{ Sleep problems } \\
\cline { 2 - 4 } & No (quantity/\%) & Yes (quantity/\%) & Total \\
\hline Study group (quantity/\%) & $53.3 \%$ & $46.7 \%$ & 240 \\
\hline Control group (quantity/\%) & $65.4 \%$ & $34.6 \%$ & 734 \\
\hline Total & 608 & 366 & 974 \\
\hline
\end{tabular}

No statistically significant relationship was found between overweight and obesity and ESS scores $(\mathrm{p}=0.2)$ or SQS scores $(\mathrm{p}=0.07)$.

Seeking additional portions of food. The study also considered nutritional habits, including the tendency to snack between meals. $35 \%$ of adolescents were shown to seek extra portions of food during the day.

Sleep disorders in adolescents were significantly related to seeking additional portions of food and snacking between meals. As many as $55.9 \%$ of adolescents with subjectively reported sleep problems and $44.1 \%$ of persons $(\mathrm{p}=0.00)$ without them sought out additional portions of food.

In the case of persons with overweight and obesity (study group) and reported sleep problems, there was an even higher statistically significant difference $(\mathrm{p}=0.00)$ for eating additional portions of food. In the study group, the number of persons with subjectively assessed sleep problems who ate additional portions of food was $65.9 \%$, and accounted for $34.1 \%$ in the group without such problems. In the control group (without overweight and obesity), the number of persons seeking additional portions was $50.2 \%$ and $49.8 \%$, respectively (Tab. 2) $(\mathrm{p}=0.00)$.

Table 2. Relationship between subjectively assessed sleep problems and seeking additional portions of food in the study and control group.

\begin{tabular}{lccc}
\hline \multirow{2}{*}{ Additional portions of food } & \multicolumn{3}{c}{ Sleep problems } \\
\cline { 2 - 4 } & No (quantity/\%) & Yes (quantity/\%) & Total \\
\hline STUDY GROUP & & & \\
\hline No (quantity/\%) & $73.5 \%$ & $26.5 \%$ & 117 \\
\hline Yes (quantity/\%) & $34.1 \%$ & $65.9 \%$ & 123 \\
\hline In total & 128 & 112 & 240 \\
\hline CONTROL GROUP & & & \\
\hline No (quantity/\%) & $72.1 \%$ & $27.9 \%$ & 516 \\
\hline Yes (quantity/\%) & $49.8 \%$ & $50.2 \%$ & 218 \\
\hline Total & 481 & 253 & 734 \\
\hline
\end{tabular}

ESS score was shown to be significantly different $(p=0.00)$ for students seeking additional portions of food compared to those who did not (6.22 \pm 4.05 points vs $5.42 \pm 3.94$ points). Overweight and obesity increased the ESS score difference between students snacking and those who did not $(6.44 \pm 4.35$ vs $5.27 \pm 4.15$ points). It was also shown that adolescents who were seeking additional portions of food had worse quality 
of sleep assessed by SQS, compared to adolescents who did not seek additional food $(29.54 \pm 7.81$ points vs $27.30 \pm 7.01$ points) $(\mathrm{p}=0.00)$.

Nutritional choices. It was shown that when making nutritional choices, only some of the studied adolescents (26.5\%) sought low-calorie and low-fat products. No statistically significant relationship was found between seeking energy-restricted products and overweight, obesity $(\mathrm{p}=0.3)$ or sleep problems reported in the subjective assessment $(\mathrm{p}=0.06)$, as well as ESS $(\mathrm{p}=0.07)$ and SQS scores $(\mathrm{p}=0.1)$.

Chronic fatigue. It was shown that over half of the adolescents (59.1\%) reported the occurrence of chronic fatigue. As many as $70.5 \%$ of students reporting sleep problems also reported chronic fatigue. Furthermore, the feeling of tiredness was related to the ESS scores, which were significantly higher for adolescents reporting chronic fatigue $(6.43 \pm 4.12$ points) compared to those who did not $(4.64 \pm 3.55$ points) $(\mathrm{p}=0.00)$.

SQS scores were similarly higher for students experiencing chronic fatigue ( $30.44 \pm 7.15$ points) compared to the group which did not report it $(24.69 \pm 6.32$ points) $(\mathrm{p}=0.00)$.

Reduced concentration and learning difficulties. As many as $36.3 \%$ of adolescents reported problems with concentration and difficulties in learning. Sleep disorders intensified those problems significantly $-43.2 \%$ of students reporting sleep problems were afflicted with disrupted concentration and difficulties in learning $(p=0.00)$. Overweight and obesity statistically significantly $(\mathrm{p}=0.00)$ affected these relations as many as $46 \%$ of overweight and obese persons reported concentration and learning problems.

ESS scores were significantly higher for adolescents reporting reduced concentration and learning difficulties (6.78 \pm 4.26 points), compared to the group who did not report such problems $(5.08 \pm 3.70)(\mathrm{p}=0.00)$. Similarly, the quality of sleep was found to be considerably worse among the group of students with concentration and learning problems (31.40 \pm 7.38 points), in comparison to the students who did not report those $(26.20 \pm 6.68$ points $)(p=0.00)$.

\section{DISCUSSION}

The presented study shows that a significant proportion of 16-18-year-old students from Silesian schools suffered from excess body weight. This result is consistent with the latest WHO data [1].

It is difficult to develop one simple indicator to measure overweight and obesity in children and adolescents due to the fact they undergo a series of physiological changes as they grow. In Poland, growth charts developed as part of the OLAF project are used to assess overweight and obesity [17]. Various cut-off points used to determine overweight and obesity among adolescents are provided in the literature [18]. In the research to allow the comparison of results for studies outside of Poland, the norms recommended by the WHO were used because they are commonly applied in international studies. Questionnaire methods were used regarding the study of sleep disorders.

Generally, the most accurate in the study of sleep are instrumental methods, e.g. polygraphy or research involving actigraph, although they may have limited use in clinical research because of the cost and complexity involved [19]. In the population sleep study, mainly questionnaire methods are used which evaluate sleep duration, night awakenings, as well as states during the day, e.g. feeling of drowsiness or involuntary falling asleep. In the questionnaires or surveys, the subjective feelings of the respondents are assessed. These methods were repeatedly compared, and as shown, may be applicable for both individual evaluation of patients in clinical practice, as well as clinical research $[19,20]$.

In the current study, 3 types of questionnaires were used: author's survey, ESS sleepiness scale, and SQS sleep quality scale, which revealed that a large proportion of young people reported sleep problems, suffer from excessive daytime sleepiness as determined by ESS scale and reduced sleep quality in the SQS scale. This is consistent with many reports worldwide that identify the growing problem of sleep disorders among young people $[7,8,21]$. In Polish literature, there are only a few publications on the occurrence of sleep disorders in this group $[20,22]$.

The current study confirmed a relationship between abnormal body weight, sleep disorders, and gender. Boys had a higher BMI than girls, which is consistent with the results of the Health Behaviour in School-aged Children (HBSC) study performed in Poland in 2018 [4]. On the other hand, sleepiness in ESS scores and sleep quality in SQS scores were shown to be higher among girls. This is confirmed for the female gender by most of the publications, regardless of the age groups studied $[23,24]$.

Additionally, the presented study confirmed a relationship between sleep disorders, excess body weight, and type of school attended by the adolescents. It turned out that the highest proportion of overweight and obese students occurred in technical schools and vocational schools, where sleep disorders were also more prevalent considering subjectively assessed sleep problems and worse sleep quality. These parameters were considerably better in high schools, which may indicate a higher health awareness of high school students or better pro-health education, but this should be the subject of further research.

The current study also demonstrated a relationship between abnormal body weight and sleep problems in the subjective assessment. Almost half of the students with overweight and obesity reported those problems compared to $1 / 3$ of students with normal body weight. Numerous studies showed that sleep disorders may be connected not only with overweight but with abnormal nutritional behavior of adolescents [25, $26,27]$. Which shows that reduced duration of sleep and its disturbed continuity are related to the increased risk of snacking during the day, as well as during the night $[28,29]$.

The current study confirmed that more than half of the adolescents with subjectively assessed sleep problems were seeking additional portions of food. In the group of adolescents additionally overweight and obese, that number was even higher. The study simultaneously confirmed that seeking additional portions of food was related to worse quality of sleep and intensified daytime sleepiness. Excess body weight in the adolescents who participated in the study contributed to an even stronger relationship of that type. On the one hand, this may be attributed to a higher inclination of overweight and obese persons to snack while waiting to fall asleep, which over time results in an increase in body weight; whereas on the other hand, poor quality of sleep and insufficient duration may affect the secretion of hormones 
by adipose tissue (leptin and ghrelin) which may result in appetite disturbance [30].

There are many publications dedicated to the relationship between length and quality of sleep and nutritional choices. Young people who slept less than $7 \mathrm{~h}$ at night ate fast-food meals more often, ate more high-calorie snacks, and more rarely sought fruits, vegetables, and low-calorie products $[31,32,33]$. The presented study showed that adolescents do not have healthy nutritional habits, and only $26.5 \%$ of the surveyed persons ate low-calorie products. This might be a result of insufficient knowledge among students related to the calorific value of consumed products.

It was demonstrated that the occurrence of sleep problems, together with ESS and SQS scores, were related to a chronic sensation of fatigue, reduced concentration, and difficulties in learning among students. Overweight and obesity had a significant impact on this relation in the group reporting sleep problems in the subjective assessment.

\section{CONCLUSIONS}

The problem of excess body weight is a very alarming phenomenon, since it affects $1 / 4$ of youth from uppersecondary schools. Almost half of the students with overweight and obesity reported sleep problems in the subjective assessment, which is connected with the type of school attended. More than $1 / 3$ of adolescents with excess body weight, who also sought additional portions of food, exhibited sleep problems, excessive daytime sleepiness, and impaired sleep quality. One in three students in uppersecondary school suffered from sleep disorders. Excess body weight seemed to exacerbate concentration problems and learning difficulties in young people.

Due to the scale of the problem, it is important to implement prophylaxis as early as possible. Measures including health education and promotion of good sleep could improve the life quality of young people.

\section{REFERENCES}

1. Obesity and overweight [Internet]. World Health Organization. World Health Organization; 2018 [cited 2019 Dec 15]. Available from: https:// www.who.int/news-room/fact-sheets/detail/obesity-and-overweight.

2. Ritchie H, Roser M. Obesity [Internet]. Our World in Data. 2017 [cited 2019 Dec 15]. Available from: https://ourworldindata.org/obesity.

3. Piekarzewska M, Wieczorkowski R, Zajenkowska-Kozłowska A. Health status of population in Poland in 2014. CSO, Social Surveys and Living Conditions Department. Warszawa; 2016. Polish.

4. Mazur J, Małkowska-Szkutnik A. Zdrowie i zachowania zdrowotne młodzieży szkolnej w Polsce na tle wybranych uwarunkowań socjodemograficznych. Wyniki badania HBSC. Instytut Matki i Dziecka. Warszawa; 2014. Polish.

5. American Academy of Sleep Medicine. International Classification of Sleep Disorders, Third edition. Diagnostic and Coding Manual. 2014.

6. Wu Y, Zhai L, Zhang D. Sleep duration and obesity among adults: a meta-analysis of prospective studies. Sleep Med. 2014; 15(12): 1456-62. doi:10.1016/j.sleep.2014.07.018.

7. Keyes KM, Maslowsky J, Hamilton A, Schulenberg J. The Great Sleep Recession: Changes in Sleep Duration Among US Adolescents, 19912012. Pediatrics. 2015; 135(3): 460-8. doi:10.1542/peds.2014-2707.

8. Kronholm E, Puusniekka R, Jokela J, Villberg J, Urrila AS, Paunio $\mathrm{T}$, et al. Trends in self-reported sleep problems, tiredness and related school performance among Finnish adolescents from 1984 to 2011. J Sleep Res. 2014 Apr; 24(1): 3-10. https://doi.org/10.1111/jsr.12258.

9. Błońska B, Gotlib J. Występowanie zaburzeń snu wśród studentów. Wydawnictwo UR. 2012;4:487-497. Polish.
10. Fatima Y, Doi SAR, Mamun AA. Longitudinal impact of sleep on overweight and obesity in children and adolescents: a systematic review and bias-adjusted meta-analysis. Obes Rev. 2015; 16(2): 137-49. https:// doi.org/10.1111/obr.12245.

11. Chen T, Wu Z, Shen Z, Zhang J, Shen X, Li S. Sleep duration in Chinese adolescents: biological, environmental, and behavioral predictors. Sleep Med. 2014; 15(11): 1345-53. doi:10.1016/j.sleep.2014.05.018.

12. Kuczmarski RJ, Ogden CL, Guo SS, Grummer-Strawn LM, Flegal KM, Mei Z et al. 2000 CDC Growth Charts for the United States: methods and development. Vital Health Stat. 2002; 11(246): 1-190.

13. Murray MW. A new method for measuring daytime sleepiness scale. Sleep. 1991; 14: 540-545. doi:10.1093/sleep/14.6.540

14. Kasperczyk J, Jośko J. The estimation of sleep quality by means of SEN questionnaire. Środowiskowe źródła zagrożeń zdrowotnych. Wydawnictwo Polihymnia. Lublin;2007:225-227.

15. About the ESS [Internet]. Epworth Sleepiness Scale. [cited 2019 Dec 15]. Available from: http://epworthsleepinessscale.com/about-the-ess/. 16. Höglund A, Hagell P, Broman J, Pålhagen S, Sorjonen K, Fredrikson S. A 10-year follow-up of excessive daytime sleepiness in Parkinson's Disease. Parkinsons Dis. 2019; 2019:1-7. doi:10.1155/2019/5708515.

17. Kułaga Z, Różdżyńska-Świątkowska A, Grajda A, Gurzkowska B, Wojtyło M, Góźdź M et al. Siatki centylowe dla oceny wzrastania i stanu odżywienia polskich dzieci i młodzieży od urodzenia do $18 \mathrm{roku}$ życia. Stand Med, Pediatr. 2015; 12: 119-135. Polish.

18. Malczyk E. The review of research methods used to assess nutritional status of children and youth in Poland in period 2005-2015. Ann Acad Med Siles. 2016; 70: 80-83. Polish. doi:10.18794/aams/58972.

19. Luyster FS, Choi J, Yeh C-H, Imes CC, Johansson AE, Chasens ER. Screening and evaluation tools for sleep disorders in older adults. Appl Nurs Res. 2015; 28(4): 334-40. doi:10.1016/j.apnr.2014.12.007.

20. Lau K, Jośko J. Zaburzenia snu jako problem zdrowia publicznego. Zdr Publ. 2010; 120(2): 199-202. Polish.

21. Verkooijen S, Vos ND, Bakker-Camu BJ, Branje SJ, Kahn RS, Ophoff RA, et al. Sleep Disturbances, Psychosocial Difficulties, and Health Risk Behavior in 16,781 Dutch Adolescents. Acad Pediatr. 2018; 18(6): 655-61. doi:10.1016/j.acap.2018.03.003.

22. Kasperczyk J, Jośko J, Cichoń-Lenart A, Lenart J. Epidemiologia zaburzeń snu u młodzieży mieszkającej na Górnym Śląsku. Sen. 2006; 6(1): 8-13. Polish.

23. Lehnkering $\mathrm{H}$, Siegmund R. Influence of chronotype, season, and sex of subjects on sleep behavior of young adults. Chronobiol Int. 2007; 24: 875-888. doi:10.1080/07420520701648259.

24. Hung HC, Yang YC, Ou HY, Wu JS, Lu FH, Chang CJ. The association between self-reported sleep quality and overweight in a Chinese population. Obesity. 2013; 21(3): 486-92. doi:10.1002/oby.20259.

25. Sadowska J, Daniel I. Konsekwencje zdrowotne nieprawidłowości w żywieniu dzieci i młodzieży w wieku gimnazjalnym. Kosmos. Problemy nauk biologicznych. 2016; 65(4): 553-561. Polish.

26. Bonuck K, Chervin RD, Howe LD. Sleep-disordered breathing, sleep duration, and childhood overweight: a longitudinal cohort study. J Pediatr. 2015; 166(3): 632-639. doi:10.1016/j.jpeds.2014.11.001.

27. Peltzer K, Pengpid S. Sleep duration, sleep quality, body mass index and waist circumferences among young adults from 24-low and middleincome and two high-income countries. Int J Environ Res Public Health. 2017; 14(6). doi:10.3390/ijerph14060566.

28. Burt J, Dube L, Thibault L, Gruber R. Sleep and eating in childhood: a potential behavioral underlying the relationship between poor sleep and obesity. Sleep Med. 2014; 15(1): 71-75. doi:10.1016/j.sleep.2013.07.015.

29. He F, Bixler EO, Liao J, Berg A, Imamura Kawasawa Y, FernandezMendoza J et al. Habitual sleep variability, mediated by nutrition intake, is associated with abdominal obesity in adolescents. Sleep Med. 2015; 16(12): 1489-1494. doi:10.1016/j.sleep.2015.07.028.

30. Grandner M, Seixas A, Shetty S, Shenoy S. Sleep Duration and Diabetes Risk: Population Trends and Potential Mechanisms. Curr Diab Rep. 2016; 16(11). doi:10.1007/s11892-016-0805-8.

31. Stalmach M, Jodkowska M, Radiukiewicz K, Oblacińska A. Sleep duration among students and its association with health behaviors. Hygeia Public Health. 2016; 51(2): 179-186. Polish.

32. Khan MK, Chu YL, Kirk SF, Veugelers PJ. Are sleep duration and quality associated with diet quality, physical activity, and body weight status? A population-based study of Canadian children. Can J Public Health. 2015; 106(5): 277-282. doi:10.17269/cjph.106.4892.

33. Lu Q, Hou F, Sun Y, Zhang Z, Tao F. Relations between duration of sleep, dietary patterns and the prevalence of overweight/obesity among 11-13 year-olds in Xuzhou, Jiangsu province of China. Zhonghua Liu Xing Bing Xue Za Zhi. 2014; 35(4): 381-385. 